\title{
The use of stalagmite geochemistry to detect past volcanic eruptions and their environmental impacts
}

\author{
Silvia Frisia ${ }^{1 *}$, S. Badertscher ${ }^{2}$, A. Borsato ${ }^{1,3}$, J. Susini ${ }^{4}$, O.M. Göktürk ${ }^{3}$, H. Cheng ${ }^{5}$, R.L. Edwards ${ }^{5}$, J. Kramers ${ }^{2}$, O. Tüysüz and D. Fleitmann ${ }^{2}$ \\ ${ }^{1} S c h o o l$ of Environmental and Life Sciences, University of Newcastle, Australia; Silvia.Frisia@newcastle.edu.au \\ ${ }^{2}$ Institute of Geological Sciences, University of Bern, Switzerland; ${ }^{3}$ Museum of Natural Sciences, Trento, Italy; ${ }^{4}$ European Synchrotron Radiation Fa- \\ cility, Grenoble, France; ${ }^{5}$ Department of Geology and Geophysics, University of Minnesota, Minneapolis, USA; ${ }^{6}$ Eurasia Institute of Earth Sciences, \\ Istanbul Technical University, Turkey
}

Our knowledge of past volcanic eruptions and their climatic impact is still far from complete. Establishing a clear link between volcanism and anomalous tree ring growth is difficult (Pearson et al., 2005), and ice core chemical signals do not match the historical record of eruptions or do not allow recognition of distal eruptions (Zielinski, 2000; Oppenheimer, 2003). Evidence for a causal connection between past volcanism and climate anomalies relies on the robust correlation between climate proxies and chemical fingerprinting of past eruptions within the same well-dated archive. Stalagmite geochemistry has the potential for providing precisely dated and spatially well-distributed records of past volcanic eruptions and of their environmental impacts (Frisia et al., 2005).

The chemical signal that is the most likely proxy of past volcanic eruptions is Sulfur (S) concentration variability in the carbonate. The $\mathrm{S}$ emitted from volcanic eruptions to the atmosphere oxidizes to sulfate and reaches the soil as wet and dry deposition, or as ions adsorbed onto ash particles. The propagation of the atmospheric sulfate signal from the surface to the cave depends on the transmissivity of the karst aquifer (i.e., the hydraulic conductivity multiplied by the thickness of the aquifer). Caves cut in fissured limestone overlain by relatively thin soil with large interconnected pores ensure fast transmission, and in a few days or a few months after the eruption, the growing calcite will form from waters with a higherthan-background concentration of sulfate. Sulfur in the form of sulfate (S-sulfate) will be incorporated either in the calcite crystal lattice, or as micro-inclusions in the stalagmite. A volcanically induced increase in local acidity levels may also mobilize $\mathrm{S}$ adsorbed onto ash or associated with wet deposition and make it available to the ecosystem. This may result in a lagged response in the speleothem compared to the atmosphere, associated with the mineralization of sulfate in organic form followed by re-oxidation to sulfate. Volcanic eruptions are, therefore, likely to be recorded in stalagmites by both a narrow S-sulfate peak coinciding with the year of a large eruption, or by a broader S-sulfate peak in the years immediately following the eruption (Frisia et al., 2005; Wynn et al., 2008).

\section{S concentration in speleothems: Analytical methods}

In order to resolve $S$ peaks related to volcanic eruptions, a very high spatial resolution, low limit of detection (ppm to ppb) and precise correlation between growth laminae (microstratigraphy) and geochemical signals must be achieved. Synchrotron radiation based micro $\mathrm{X}$-ray fluorescence (SR- $\mu \mathrm{XRF}$ ) microscopy coupled with X-ray

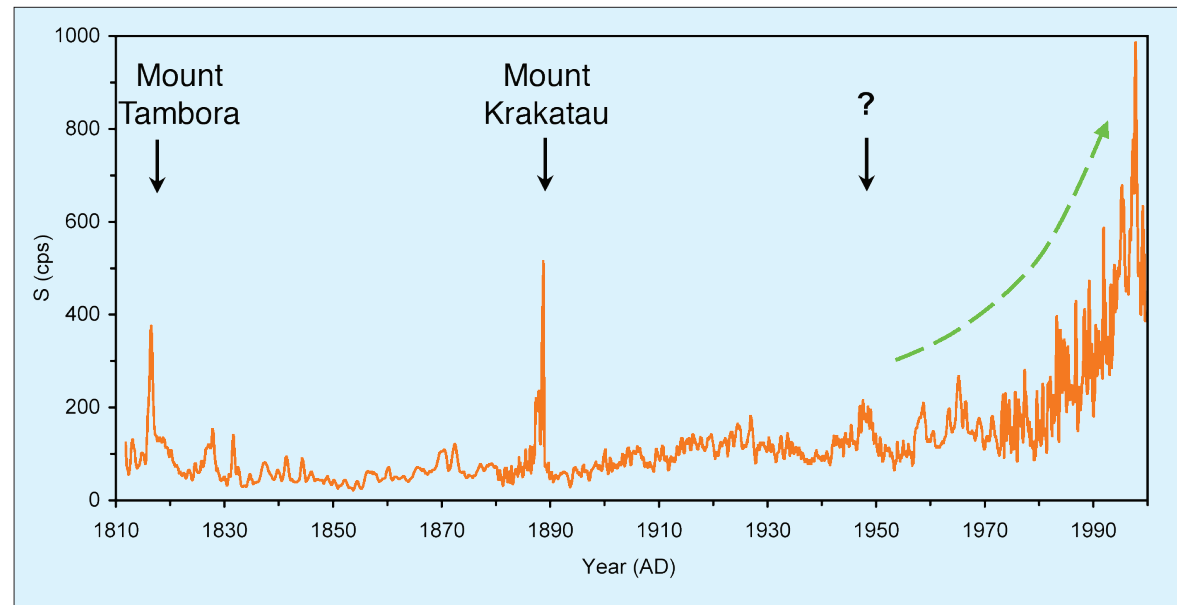

Figure 1: Results of the SR- $\mu$ XRF analyses of S-sulfate in the 1810-2000 AD portion of a stalagmite from Grotta di Ernesto (N. Italy). Arrows indicate that sulfate concentration peaked in the years 1815-1816, 1884-1888, and 1947. These peaks can be ascribed to atmospheric S load increases following the Tambora, Krakatau and (possibly) Hekla eruptions, respectively. The pronounced increasing trend in S-sulfate concentration (counts per second; cps) after the year 1960 is due to anthropogenic sulfate emissions (Frisia et al., 2005) and masks any more recent volcanic-related S-sulfate peaks. absorption near-edge spectrometry allow for high spatial resolution, low limits of detection, assessment of the molecular environment of $\mathrm{S}$ and precise location of the analyzed regions (Borsato et al., 2007). This technique appears to be best suited for annually resolved sulfate variability in stalagmites. The use of SR- $\mu$ XRF to detect $\mathrm{S}$-sulfate in stalagmites from different geographic locations highlights both direct and delayed responses of the ecosystem to the emission of $\mathrm{S}$ in the atmosphere after volcanic eruptions.

\section{Tambora and Krakatau recorded in a stalagmite from N. Italy}

Annually laminated stalagmites from Grotta di Ernesto, located at ca. $1160 \mathrm{~m}$ asl in NE Italy, show distinct $S$ peaks in the years 1815-1816, 1884-1888, and 1947 (Fig. 1). The age model is based on annual lamina counting and radiometric dating. Quantification of the $S$ content from synchrotron data (counts per second; cps) was carried out by calibration with five dissolved specimens from the same samples, analyzed using high-mass resolution inductively coupled mass spectrometry (ICP-MS; Borsato et al., 2007).

The 1815 to 1816 AD increase in Ssulfate from ca. 15 to ca. $30 \mathrm{ppm}$ coincides with the eruption of Mount Tambora in Indonesia (April 1815). However, a connection between volcanism, stalagmite growth anomaly and climate cannot be attested as the Tambora eruption falls within a Little Ice Age portion of the stalagmite that is characterized by very thin annual laminae $(2-10 \mu \mathrm{m})$ indicative of low mean annual temperatures (Frisia et al., 2003). In 1884-1888, sulfate peaked to values between ca. 10 and 40 ppm, then returned rapidly (within ca. 2 years) to values below $10 \mathrm{ppm}$. This peak coincides with the eruption of Mount Krakatau (Indonesia) in August 1883, and falls within a portion of the stalagmite where lamina thickness averages $100 \mu \mathrm{m}$. The thickness decreases abruptly throughout the 1884-1888 time span to less than $50 \mu \mathrm{m}$, which supports the causal connection between a volcanic eruption, sulfate aerosol and shortlived cooling. The sulfate peak in the 1947 lamina may correspond to the eruption 
of Hekla (March 1947) in Iceland and is followed by a short-lived diminution in lamina thickness from the average of 100 $\mu \mathrm{m}$ to ca. $80 \mu \mathrm{m}$. Since 1960 , the anthropogenic S-sulfate signal is overwhelming and masks possible peaks related to more recent volcanism.

\section{The Santorini eruption recorded in a N. Turkey stalagmite}

The stalagmite of Grotta di Ernesto shows, through a decrease in lamina thickness and variability in calcite sulfate concentration, a rapid climatic response (cooling) to the rapid, short-lived stratospheric sulfate aerosol emissions generated by the aforementioned volcanic eruptions. In contrast, a stalagmite from Sofular Cave in western Anatolia, Turkey, shows a delayed response (Fig. 2). The S-sulfate investigation of this sample focused on a well-dated portion of the stalagmite encompassing the Santorini eruption, from ca. 3350 -3800 years before 2008. The Santorini eruption, which is believed to have spread a huge layer of ash over the Eastern Mediterranean region, has been recently dated at $1627-1600$ BC (3633-3608 BP) on the basis of a wiggle-matched sequence of radiocarbon-dated olive tree ring groups (Friedrich et al., 2006).

A distinct S-sulfate peak, here reported in cps as the calibration has yet to be performed, occurs between 3550 and 3600 BP. This indicates that increased S levels had been available for mobilization from the surface to the subsurface for several decades. The $\mathrm{S}$ peak detected in the Sofular stalagmite could thus be related to the environmental acidity increase following the eruption. The question remains about timing of the Santorini eruption. The broad S-sulfate peak immediately follows a distinctive, short-lived peak in $\delta^{13} \mathrm{C}$, which shifts to more positive values at ca. $3610 \mathrm{BP}$ and reaches its maximum (of ca. $0.8 \%$ ) at ca. 3600 BP. A preliminary interpretation is that the $\delta^{13} \mathrm{C}$ peak may be related to vegetation stress following the eruption. Based on the interpretation of millennial- to secular-scale $\delta^{13} \mathrm{C}$ changes recorded in the stalagmite from Sofular Cave, this stress is most likely related to a dry spell (Badertscher et al., in prep.). The timing of the Santorini eruption in the Sofular record is thus marked by a rapid, short-lived (few years) $\delta^{13} \mathrm{C}$ shift to more positive values (ca. 3010 BP). Given the uncertainties related to different dating methods, the dating of the Santorini eruption from the Sofular record is similar to that obtained by Friedrich et al. (2006), and supports an eruption on Santorini in the late $17^{\text {th }}$ or early $16^{\text {th }}$ century $B C$.

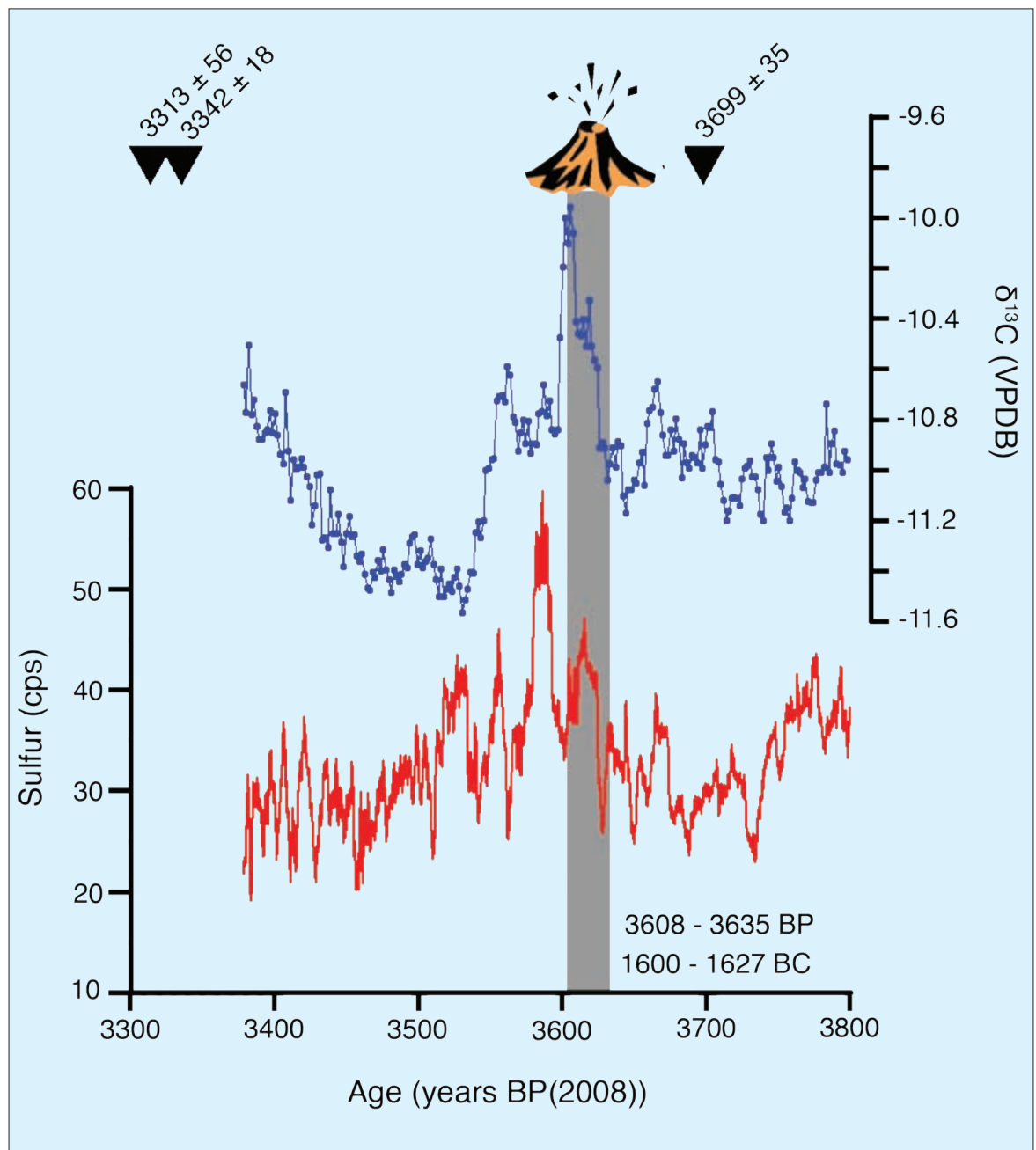

Figure 2: The effects of the Santorini eruption recorded by SR- $\mu$ XRF analyses of S-sulfate in the ca. 3350-3800 BP portion of the Sofular stalagmite from Anatolia (Turkey). Note that the peak in S concentration follows a rapid shift of the inverted $\delta^{13} \mathrm{C}$ curve to more positive values, which can be related to vegetation stress. The gray shaded area marks the timing of the Santorini eruption as given by Friedrich et al., 2006.

\section{Future work}

High-resolution pilot studies of S-sulfate concentration of precisely dated stalagmites indicate that there is a high potential for studying the timing and climatic/ environmental impact of massive volcanic eruptions.

The ability to extract a causal effect between volcanic eruptions and atmospheric cooling relies on the unequivocal interpretation of the climate proxy data variability, which coincides with S-sulfate peaks in well-dated stalagmites. In the case of the stalagmite from Grotta di Ernesto, for example, the effects of the Tambora eruption cannot be distinguished from a general cooling trend that characterized the late Little Ice Age in the Alps. The Sofular record highlights that the timing of an eruption may not exactly coincide with the onset of a S-sulfate peak, probably because of the delayed rise in acidity levels following the eruption. The use of stalagmites for the evaluation of global and regional effects of major volcanic eruptions thus has some issues to overcome. However, we believe that a multi-proxy, multi- disciplinary approach will solve some of the problems concerning the timing and effects of past volcanism.

\section{References}

Badertscher, S., Fleitmann, D., Frisia, S., Borsato, A., Cheng, H., Edwards, R.L., Göktürk, O.M., Tüysüz, O. and Kramers, J., in prep.: Santorini eruption recorded in a stalagmite from Sofular Cave, Northern Turkey.

Borsato A., Frisia, S., Fairchild I.J., Somogyi A. and Susini J., 2007: Trace element distribution in annual stalagmite laminae mapped by micrometer-resolution X-ray fluorescence: implications for incorporation of environmentally significant species, Geochimica et Cosmochimica Acta, 71: 1494-1512.

Friedrich, W.L., Kromer, B., Friedrich, M., Heinemeier, J., Pfeiffer, T. and Talamo, S., 2006: Santorini eruption radiocarbon dated to 1627-1600 B.C., Science, 312: 548.

Frisia, S., Borsato, A., Fairchild, I.J. and Susini, J., 2005: Variations in atmospheric sulphate recorded in stalagmites by synchrotron micro-XRF and XANES analyses, Earth and Planetary Science Letters, 235: 729-740.

Zielinski, G.A., 2000: Use of paleo-records in determining variability within the volcanism-climate system, Quaternary Science Reviews, 19: 417-438.

For full references please consult:

www.pages-igbp.org/products/newsletters/ref2008_3.html 